\title{
DIGITALCOMMONS
}

—@WAYNESTATE-

Wayne State University

\section{Piecewise Regression Analysis of Secular Change in the Maximum Femoral Vertical Head Diameter of American White Males and Females}

Sandra Cridlin

Department of Medical Assisting, South College, Knoxville, TN, scridlin@southcollegetn.edu

\section{Recommended Citation}

Cridlin, Sandra, "Piecewise Regression Analysis of Secular Change in the Maximum Femoral Vertical Head Diameter of American White Males and Females" (2017). Human Biology Open Access Pre-Prints. 88.

http://digitalcommons.wayne.edu/humbiol_preprints/88

This Open Access Preprint is brought to you for free and open access by the WSU Press at DigitalCommons@WayneState. It has been accepted for inclusion in Human Biology Open Access Pre-Prints by an authorized administrator of DigitalCommons@WayneState. 
Title: Piecewise Regression Analysis of Secular Change in the Maximum Femoral Vertical Head Diameter of American White Males and Females

Author: Sandra Cridlin, M.A.

Institution: South College, Knoxville, Tennessee, 37909

Corresponding author: Sandra Cridlin, scridlin@southcollegetn.edu

Abbreviated title: Secular change in femoral head diameter among white Americans

Keywords: Secular change, femoral head diameter, LOESS regression, piecewise regression

Issue: 88.1

\section{Contact Information:}

Sandy Cridlin

South College

3904 Lonas Drive

Knoxville, TN 37909

scridlin@southcollegetn.edu

865-251-1870

Pre-print version. Visit http://digitalcommons.wayne.edu/humbiol/ after publication to acquire the final version. 


\begin{abstract}
Objectives: Osteometric measurements of the femur are consistently used for the estimation of stature, sex, and race in the construction of demographic profiles. The presence of positive or negative changes in the size of the maximum vertical diameter of the femoral head could potentially affect the validity of such profiles. Additionally, changes in femoral head size may be an indicator of the socioeconomic status, health, and nutrition of a population over periods of time.

Methods: Two large datasets consisting of white male and white female femoral vertical head diameter measurements with birth years spanning 1841 to 1990 are used in this study. A combination of both LOESS regression and piecewise regression models are used to determine the presence of secular changes in femoral head size. Tests of the residuals were also conducted to assess normality of the data and goodness-of-fit of the nonlinear models.

Results and Conclusions: The results indicate that white males and females experienced nonsignificant increases in femoral head diameter size prior to 1920 and significant decreases in size thereafter. The results of this study are consistent with other studies that have identified changes in body and skeletal morphology. Considerable changes and improvements in environmental conditions that humans have experienced since the mid-nineteenth century likely contribute to the decrease in femoral head size observed in this study.
\end{abstract}

Pre-print version. Visit http://digitalcommons.wayne.edu/humbiol/ after publication to acquire the final version. 
The femur has been perhaps the most studied of all the long bones in the human body (Krogman and Işcan 1986). The femoral head in particular has been the subject of numerous studies investigating morphology and biomechanical function. Asala (2001) observed that the femoral head diameter may be the most sexually dimorphic part of the femur. The utility of osteometric measures of the femoral head for the determination of sex was recognized in the late nineteenth century (Stewart 1979). While sexual dimorphism is evident in femoral head size, differences may also be attributed to ethnicity. American whites have larger femora with larger head diameters than blacks and American Indians (Gill 2001), and when matched for age, height, and weight, black women were found to have significantly smaller femoral head widths than white women (Theobald et al. 1998).

Following Wolff's law, variations in shape of the proximal femur may represent a physiological response to forces exerted by muscle when no pathology is present (Clark et al., 1987). Because bone is dynamically remodeled throughout life, the bone mass, density, and (consequently) the geometry of the proximal femur may change with age. Ruff et al. (1991) concluded that changes in mechanical loading of the proximal femur over the lifespan are more likely to produce changes in cross-sectional diaphyseal geometry rather than changes in articulation size. The use of femoral head size as an indicator of morphological change during growth and development in response to environmental pressures may be ideal as head size has been found to be highly correlated with body weight attained by eighteen years of age, and size does not increase in response to additional mechanical loading beyond early adulthood (Ruff et al. 1991).

The value of femoral metric measures for stature estimation is widely accepted and appreciated by anthropologists. Regression equations for stature estimation have been calculated from measurements of overall femur length (Hauser et al., 2005; Prasad et al., 1996; Trotter and Gleser, 1952). Furthermore femur neck length, the neck-shaft angle, vertical diameter of the head, and intertrochanteric apical axis measures are significantly positively correlated with femur length and the final version. 
stature (Giroux and Wescott, 2008; Prasad et al., 1996). Observable and measurable differences in various aspects of femoral morphology and size have been employed to discriminate ethnicity and sex among individuals and populations. It should be noted that the determination of sex based on osteometric measures can be inherently tenuous as some measures can fall within an intermediate range of variation for both sexes (Krogman and Işcan, 1986).

Anthropologists rely on previously established parameters to construct estimates of ethnicity, sex, and stature for unidentified skeletal remains. Anthropometric measures of the femur are instrumental in forensic and historic demographic assessments. Traditional standards used today for classification and estimation purposes consist of formulae derived from metric data collected mainly from femora belonging to persons now curated as individuals that comprise historic skeletal collections (Krogman and Işcan, 1986). Discriminant functions computed from osteological measurements of the femoral head for sex estimation are routinely utilized as standards for the assessment of sex for both historic and modern forensic skeletal remains; however, like other standards, they too were derived from historic skeletal samples (Bass, 1994; Krogman and Işcan, 1986; Stewart, 1979). Morphological changes over time can affect the accuracy of standards generated from historic data. As such, the recognition of positive or negative secular trends is important since changes in morphology can potentially affect the utility of data utilized for constructing demographic profiles. Research indicates that the demographic composition of most anatomical reference collections makes them inappropriate for constructing profiles of modern Americans (Ousley and Jantz, 1998; Ayers, Jantz, and Moore-Jansen, 1990; Ericksen 1982). Significant morphological changes occurring throughout the skeleton could indicate that current methodologies and standards utilized by anthropologists for identification and demographic analysis require population-specific and temporally-specific revisions. The necessity of a modern comparative skeletal reference sample to examine the extent that secular change is occurring in the United States and the need for modern population-specific parameters derived from contemporary the final version. 
skeletal samples for classification purposes has already been identified (Albanese et al., 2012; Auerbach and Ruff, 2010; Frutos, 2003; Asala, 2002; Asala, 2001; Klepinger, 2001, Ousley and Jantz, 1998).

The identification of secular trends in features and geometrical aspects of the femur inform how femoral morphology changes over time within populations due to genetic and environmental factors. Past research has predominantly focused on morphological changes in the length of this bone in regard to stature (Bruns et al. 2002; Jantz and Jantz 1999; Price et al. 1987; Trotter and Gleser 1951). Jantz and Jantz (1999) found that femur length has significantly increased among white and black males and females in the United States, and white males and black females have undergone significant changes in femoral shape over time. Secular changes in femoral neck morphology have also been observed (Stojanowski and Seidemann 1999; Anderson and Trinkaus 1998; Duthie, Bruce, and Hutchison 1998; Theobald et al. 1998; O’Neill et al. 1996; Reid et al. 1994; Nilsson and Orbrant 1978). Duthie, Bruce, and Hutchison (1998) found an overall increase in the femoral length as well as significant increases in the diameter of the femoral head, and in the length and width of the femoral neck over time. The attention and focus given to these topics are most likely a reflection of the continued interest in stature as an indicative measure of health, and their relevance in understanding the increasing incidence of hip fracture and replacement among older adults (Cooper et al., 2011).

Current research and interest in secular changes in femoral head diameter for any population has been almost absent. With the exception of a study examining anatomical specimens in Scotland (Duthie et al., 1998) secular changes in femoral head diameter have received little attention. The present study examines the femoral head for evidence of secular change in American white males and females. Analyses will be used to determine if the head of the femur has increased or decreased in size over time, and to ascertain an approximate time if a change in size has occurred.

Pre-print version. Visit http://digitalcommons.wayne.edu/humbiol/ after publication to acquire the final version. 


\section{Methods}

This analysis employs piecewise regression as a method of time series analysis to identify evidence of secular change in the maximum head diameter in the femora of American white males and females. Data consisting of maximum vertical head diameters (VHD) collected from human femora from the Terry Anatomical Collection, the University of Tennessee Forensic Databank, and the M. F. Ericksen Femur Collection were utilized in this study. The M. F. Ericksen Femur Collection consists of proximal femora willed to the George Washington University Medical Center, and collected by Dr. M. F. Ericksen (Ericksen, 1982). This collection was donated to the University of Tennessee, Knoxville Department of Anthropology during the mid-1990s where it is still curated. Demographically, the collection is comprised of individuals with diverse vocations and varied socioeconomic backgrounds, making this sample somewhat more representative of the population at that time, but ethnically disparate as black males and females are markedly under-represented in this collection. Birth years of individuals in this collection range from 1841 to 1990. As shown in Table 1, these three sources of data provided a combined total sample $n=1,762$ of vertical head measures of femora from adult white males and females. Data were partitioned by sex into two groups in order to facilitate statistical analyses.

Datasets comprised of values observed sequentially through time, such as those employed for the examination of secular change, are considered time series data. Measurements that are close in time tend to also be closer or similar in value than measurements that are temporally far apart. Thus the data exhibit some sequential dependence that occurs more so than what would be expected to occur purely by chance alone. Serial correlation exists if any observations or their residuals are not independent. If the probability distribution of a dataset is the same (the mean and variance are constant) for all starting values of time, the statistical process is deemed as stationary. If the values of a data series are dependent on time, a data series that exhibits a trend is not stationary (NCSS, Kaysville, Utah).

Pre-print version. Visit http://digitalcommons.wayne.edu/humbiol/ after publication to acquire the final version. 
Linear regression is used frequently to analyze secular change. Because patterns associated with changes over time are not always linear in nature and the variables are usually autocorrelated, this statistical approach is likely to be inappropriate for the analysis of secular change. It should be assumed that measurement data that is dependent on time contains some degree of autocorrelation, and that patterns of change present in the data do not have to be linear in nature. Autocorrelation in either the data or the residuals would violate several statistical assumptions of normality associated with a linear regression model. The data in this study consists of measurements taken over time, therefore analyses specific for the assessment of time series data were warranted for this analysis. Statistical analyses were executed using a combination of computer software programs consisting of NCSS statistical software (NCSS, Kaysville, Utah), and SAS 9.2 (SAS Institute, Inc., 2009, Cary, NC).

The male and female datasets were initially tested for positive or negative first order serial correlation using the Durbin-Watson test for autocorrelation. A combination of LOESS and piecewise statistical regression methods using the individual measurements were subsequently used to assess trends in maximum vertical femoral head diameter size over time. LOESS regression using year of birth (YOB) as the independent variable and maximum vertical head diameter (VHD) as the dependent variable was employed first as a nonparametric method to survey the structure of the data for localized fluctuations in femoral head diameter size over time. Breakpoints, or points of change observed as peaks and valleys in the curvilinear slope of the regression line, signify shifts in diameter size which can be visually approximated to a time that the shift occurred. "Breakpoints are the values of $x$ where the slope of the linear function changes" (Ryan and Porth, 2007).

Using the Proc NLIN procedure in SAS (SAS Institute, Inc., 2009, Cary, NC), two linear regression models using the same dependent variable and regressor variable were then applied to the data separately above and below the visually estimated breakpoints obtained from the LOESS regression to Pre-print version. Visit http://digitalcommons.wayne.edu/humbiol/ after publication to acquire the final version. 
obtain starting parameters $(a 1, b 1, c$, and $b 2)$ for the piecewise regression model. The piecewise regression was executed using the PROC NLIN procedure in SAS (SAS Institute, Inc., 2009, Cary, NC). Convergence of the model indicates the starting parameters are a good fit for the piecewise regression. Piecewise regression accounts for more variability than a linear model as it allows for multiple linear models to be fit to the data for different ranges of the explanatory variable $(x)$. Residuals were tested for violations of independence and normality. A separate autoregressive model was applied to the residuals to determine if correlation existed among the residual values. Additionally the mean square error (MSE) of the piecewise regression was compared to the MSE obtained from an autoregressive model of the residuals to determine if the original parameters chosen to model the piecewise regression result in the best fit for the data. The application of LOESS regression combined with piecewise regression and autoregression analysis of the residuals allows for the detection of changes in size over time, the identification of an approximate time that a shift in vertical head diameter occurred, and tests for significance of those changes.

\section{Results}

Results of the Durbin-Watson test were not statistically significant at the 0.05 level for autocorrelation for the male or female dataset (Table 2).

\section{$\underline{\text { Males }}$}

A breakpoint observed as a peak in the Loess regression line was visually estimated to occur around the year 1920 (Figure 1). Using this breakpoint, two linear regression models were fit separately above and below the approximated year 1920 in order to obtain the starting parameters $(a 1=40.91297$, $b 1=0.00419, c=1920$, and b2=-0.03025) for the piecewise regression model (Table 3) (Figure 2). Convergence of the model was met indicating that the model is a good fit. Results of the piecewise model indicate that males experienced an increase in femoral head diameter prior to 1920 that is not significant $(p<0.5212)$, and a decrease in size thereafter that is significant $(p<0.0001)$ (Table 4). Testing 
of the residuals revealed that there is significant correlation among the residuals $(p<0.0001)$. However, the effects of the correlation are most likely not substantial as the mean square error (MSE) of the original model (6.5149) does not differ considerably from the MSE of the residuals (6.4105) which takes correlation into account (Table 5). Results of the Shapiro-Wilk test for normality among the residuals presented in Table 6 show that the data are normally distributed below the 1920 breakpoint $(p<0.1890)$, but are not normally distributed above the breakpoint $(p<0.0145)$.

\section{Females}

A breakpoint identified as a peak in the LOESS regression line around the year 1920 was observed (Figure 3). This estimated a breakpoint in the data was then utilized to fit two linear regression models above and below the year 1920 in order to obtain the starting parameters $(a 1=24.50070, b 1=0.00957, c=1920$, and $b 2=-0.01390)$ for the piecewise model (Table 3) (Figure 4). Convergence criteria was met for this model thus indicating that these parameters were a good fit for the model. Results of the piecewise model indicate that female femoral vertical head diameters increased in size prior to 1920 , but this increase was not statistically significant $(p<0.1683)$. After 1920, female femoral vertical head diameters have significantly decreased size $(p<0.0303)$ (Table 7). Correlation among the residuals was not significant $(p<0.1021)$. Additionally, any effects of the correlation were slight as the mean square error (MSE) of the original model (4.8013) does not differ considerably from the MSE of the residuals (4.7642) (Table 8). Results of the Shapiro-Wilk test for normality among the residuals indicate that the data are normally distributed below the 1920 breakpoint $(p<0.2998)$, and above the breakpoint $(p<0.1579)$ (Table 9).

\section{Discussion}

Based on the results of this analysis, it is apparent that American white males and females are experiencing similar patterns of change in the maximum vertical diameter of the femoral head. Both datasets revealed increases in head diameter that were not statistically significant prior to the estimated

Pre-print version. Visit http://digitalcommons.wayne.edu/humbiol/ after publication to acquire the final version. 
1920 breakpoint, and statistically significant decreases in size thereafter. These similar patterns of change identified in this study suggest that both sexes are experiencing similar environmental pressures that are acting on this particular aspect of the skeleton. It could be postulated that a decrease in size of the pelvic girdle may be occurring as the bones of the lower limb are modeled in response to biomechanical loading forces during childhood which would include upper body weight. This hypothesis is especially intriguing since decreases in vertical head diameters are occurring while rates of obesity in the population are increasing (Imes and Burke 2014). It may also be possible that femoral head size is becoming constrained while changes are occurring in the trabecular architecture of the femoral head as a compensatory mechanism to increased loading. The negative trends observed in this analysis are likely related to health, nutrition, and socioeconomic factors that would have affected the population of the United States prior to and after World War II. Prior research has shown that the United States population has undergone changes in body mass index and a reduction in stature since World War II (Komlos, 2010; Komlos and Brabec, 2011; Komlos and Lauderdale, 2007).

The employment of nonlinear methods for the identification of secular changes underscores the importance of using statistical models that fit the characteristics of the data. Linear regression has long been the standard method used to identify secular changes in various skeletal elements. Alternative statistical models should be considered an effectual and valuable alternative and employed when conducting analyses of secular trends in the human skeleton as changes that occur over time are not always unidirectional. Linear regression models for these data would have not have been appropriate for the identification of secular changes in this study due to the correlation present in the data. Furthermore, the use of a linear regression model would not have facilitated the detection of the negative change in slope of the regression lines that indicate a significant decrease in vertical head diameter observed to occur after 1920 for males and females. Additional analyses of secular changes in the maximum vertical head diameters of American black males and females using advanced statistical

Pre-print version. Visit http://digitalcommons.wayne.edu/humbiol/ after publication to acquire the final version. 
methods similar to those employed in this study would be beneficial and fundamental in ascertaining if black femoral head diameters have similarly fluctuated in size over time, and necessary to establish if the observed estimated breakpoint of 1920 identified in this study are indeed significant for both populations.

Received 4 November 2015; revision uploaded 5 April 2016.

Pre-print version. Visit http://digitalcommons.wayne.edu/humbiol/ after publication to acquire the final version. 


\section{Literature Cited}

Albanese, J., S. E. Osley, and A. Tuck. 2012. Do century-specific equations provide better estimates of stature? A test of the 19-20th century boundary for the stature estimation feature in Fordisc 3.0. Forensic Sci. Int. 219:1-3.

Anderson, J. Y. and E. Trinkaus. 1998. Patterns of sexual, bilateral and interpopulational variation in human femoral neck-shaft angles. J. Anat. 192:279-85.

Asala, S. A. 2001. Sex determination from the head of the femur of South African whites and blacks. Forensic Sci. Int. 117:15-22.

Asala, S. A. 2002. The efficiency of the demarking point of the femoral head as a sex determining parameter. Forensic Sci. Int. 127:114-118.

Auerbach, B. M., and C. B. Ruff. 2010. Stature estimation formulae for indigenous North American populations. Am. J. Phys. Anthropol. 141(2):190-207.

Ayers, H. G., R. L. Jantz, and P. H. Moore-Jansen. 1990. Giles and Eliot race discrimination functions revisited: A test using recent forensic cases. In: Skeletal Attribution of Race, G.W. Gill and S. Rhine, editors, pgs. 65-71. Maxwell Museum of Anthropology, Albuquerque.

Bass, W. M. 1995. Human Osteology: A Laboratory and Field Manual. Fourth Edition. Special Publication No. 2 of the Missouri Archaeological Society. Columbia, Missouri.

Beck, T. J., C. B. Ruff, W. W. Scott, Jr., et al. 1992. Sex differences in geometry of the femoral neck with aging: A structural analysis of bone mineral data. Calcified Tissue Int. 50:24-29.

Bruns, W., M. Bruce, G. Prescott, and N. Maffulli. 2002. Temporal trends in femoral curvature and length in Medieval and Modern Scotland. Am. J. Phys. Anthropol. 119:224-230.

Clark, J. M., M. A. R. Freeman, and D. Witham. 1987. The relationship of neck orientation to the shape of the proximal femur. J. Arthroplasty 2(2):99-109.

Pre-print version. Visit http://digitalcommons.wayne.edu/humbiol/ after publication to acquire the final version. 
Cooper, C., Z. A. Cole, C. R. Holroyd, et al. 2011. Secular trends in the incidence of hip and other osteoporotic fractures. Osteoporosis Int. 22(5):1277-1288.

Duthie, R. A., M. F. Bruce, and J. D. Hutchison. 1998. Changing proximal femoral geometry in north east Scotland: an osteometric study. Brit. Med. J. 316:1498.

Ericksen, M. F. 1982. How "representative" is the Terry Collection? Evidence from the proximal femur. Am. J. Phys. Anthropol. 59:345-350.

Frutos, L. R. 2003. Brief communication: Sex determination accuracy of the minimum supero-inferior femoral neck diameter in a contemporary rural Guatemalan population. Am. J. Phys. Anthropol. 122:123-126.

Giroux, C. L., and D. J. Wescott. 2008. Stature estimation based on dimensions of the bony pelvis and proximal femur. J. Forensic Sci. 53(1):65-68.

Gill, G. W. 2001. Racial variation in the proximal and distal femur: Heritability and forensic utility. J. Forensic Sci. 46(4):791-799.

Hauser, R., J. Smoliński, and T. Gos. 2005. The estimation of stature on the basis of measurements of the femur. Forensic Sci. Int. 147(2-3):185-190.

Hintze, J. 2004. NCSS 2004. NCSS, LLC. Kaysville, Utah, USA. www.ncss.com.

Imes, C. C. and L. E. Burke. 2014. The obesity epidemic: The United States as a cautionary tale for the rest of the world. Curr. Epidemiology Reports. 1(2): 82-88.

Meadows, Jantz L. and R. L. Jantz. 1999. Secular change in long bone length and proportion in the United States, 1800-1970. Am. J. Phys. Anthropol. 110:57-67.

Klepinger, L. L. 2001. Stature, maturation variation and secular trends in Forensic Anthropology. J. Forensic Sci. 46(4):788-790.

Pre-print version. Visit http://digitalcommons.wayne.edu/humbiol/ after publication to acquire the final version. 
Komlos, J. and M. Brabec. 2011. The trend of BMI values of US adults by deciles, birth cohorts 18821986 stratified by gender and ethnicity. Econ. Hum. Biol. 3:234-250.

Komlos, J. 2010. The recent decline in the height of African-American women. Econ. Hum. Biol. 1:58-66. Komlos, J., and B. E. Lauderdale. 2007. The mysterious trend in American heights in the $20^{\text {th }}$ century. Ann. Hum. Biol. 34(2):206-215.

Krogman, W. M., and M. Y. Işcan. 1986. The Human Skeleton in Forensic Medicine. Second Edition. Charles C. Thomas. Springfield, Illinois.

Nilsson, B. E and K. J. Obrant. 1978. Secular tendencies of the incidence of fracture of the upper end of the femur. Acta Orthop. Scand. 49(4):389-391.

O’Neill, T. W., S. Grazio, T. D. Spector, et al. 1996. Geometric measurements of the proximal femur in UK women: Secular increase between the late 1950's and early 1990's. Osteoporosis Int. 6:136-140. Ousley, S. D., and R. L. Jantz. 1998. The Forensic Data Bank: Documenting Skeletal Trends in the United States. In: Forensic Osteology: Advances in the Identification of Human Remains. Second Edition. K. J. Reichs, editor, pgs. 441-458. Charles C. Thomas. Springfield, Illinois.

Peacock, M., G. Liu, M. Carey, et al. 1998. Bone mass and structure at the hip in men and women over the age of 60 years. Osteoporosis Int. 8:231-239.

Prasad, R., S. Vettivel, L. Jeyaseelan, et al. 1996. Reconstruction of femur length from markers of its proximal end. Clin. Anat. 9:28-33.

Price, B., N. Cameron, and P. V. Tobias. 1987. A further search for a secular trend of adult body size in South African Blacks: evidence from the femur and tibia. Hum. Biol. 59(3):467-475.

Reid, I. R., K. Chin, M. C. Evans, et al. 1994. Relation between increase in length of hip axis in older women between 1950's and 1990's and increase in age specific rates of hip fracture. Brit. Med. J. 309:508-509.

Pre-print version. Visit http://digitalcommons.wayne.edu/humbiol/ after publication to acquire the final version. 
Ruff, C. B., W. W. Scott, and A.Y.-C. Liu. 1991. Articular and diaphyseal remodeling of the proximal femur with changes in body mass in adults. Am. J. Phys. Anthropol. 86:397-413.

Ryan, S. E. and L. S. Porth. 2007. A tutorial on the piecewise regression approach applied to bedload transport data. Gen. Tech. Rep. RMRS-GTR-189. Fort Collins, CO:U.S. Department of Agriculture, Forest Service, Rocky Mountain Research Station.

Stewart, T. D. 1979. Essentials of Forensic Anthropology: Especially as Developed in the United States. Charles C. Thomas. Springfield, Illinois.

Stojanowski, C. M., and R. M. Seidemann. 1999. A reevaluation of the sex prediction accuracy of the minimum supero-inferior femoral neck diameter for modern individuals. J. Forensic Sci. 44(6):12151218.

Theobald, T. M., J. A. Cauley, C. C. Gluer, et al. 1998. Black-white differences in hip geometry. Osteoporosis Int. 8:61-67.

Trotter, M. and G. C. Gleser. 1951. Trends in stature of American whites and Negros born between 1840 and 1924. Am. J. Phys. Anthropol. 9:427-440.

Trotter, M. and G. C. Gleser. 1952. Estimation of stature from long bones of American Whites and Negroes. Am. J. Phys. Anthropol. 10:463-514.

The piecewise regression analysis of maximum vertical head diameters for this paper was generated using SAS software. Copyright, SAS Institute Inc. SAS and all other SAS Institute Inc. product or service names are registered trademarks or trademarks of SAS Institute Inc., Cary, NC, USA.

Pre-print version. Visit http://digitalcommons.wayne.edu/humbiol/ after publication to acquire the final version. 
Table 1. Sample composition.

\begin{tabular}{|l|c|c|c|c|}
\hline & Terry Collection & $\begin{array}{c}\text { M. F. Ericksen } \\
\text { Collection }\end{array}$ & $\begin{array}{c}\text { UT Forensic } \\
\text { Databank }\end{array}$ & Total Sample Size \\
\hline White males & 70 & 89 & 934 & 1093 \\
\hline White females & 62 & 89 & 518 & 669 \\
\hline Total & $\mathbf{2 4 7}$ & $\mathbf{1 8 5}$ & $\mathbf{7 8 5}$ & $\mathbf{1 7 6 2}$ \\
\hline
\end{tabular}

Pre-print version. Visit http://digitalcommons.wayne.edu/humbiol/ after publication to acquire the final version. 
Table 2. Results of Durbin-Watson tests for autocorrelation.

\begin{tabular}{|l|c|c|}
\hline Parameter & Value & Rejection of H0: Rho(1) = 0? \\
\hline Durbin-Watson Value & 1.9885 & No \\
\hline Prob. Level: Positive Serial Correlation & 0.4130 & No \\
\hline Prob. Level: Positive Serial Correlation & 0.5632 & No \\
\hline & Females & No \\
\hline Durbin-Watson Value & 1.9876 & \\
\hline Prob. Level: Positive Serial Correlation & 0.4198 & \\
\hline Prob. Level: Positive Serial Correlation & 0.5503 & \\
\hline
\end{tabular}

Pre-print version. Visit http://digitalcommons.wayne.edu/humbiol/ after publication to acquire the final version. 
Table 3. Parameters used for PROC NLIN model determination.

\begin{tabular}{|l|c|c|}
\hline \multicolumn{2}{|c|}{ Parameter Estimates from Linear Regression Model Used for NLIN Procedure } \\
\hline Parameter & Males & Females \\
\hline a1 & 40.91297 & 24.50070 \\
\hline b1 & 0.00419 & 0.00957 \\
\hline c & 1920 & 1920 \\
\hline b2 & -0.03025 & -0.01390 \\
\hline
\end{tabular}

Pre-print version. Visit http://digitalcommons.wayne.edu/humbiol/ after publication to acquire the final version. 
Table 4. Piecewise regression fit results for the male dataset.

\begin{tabular}{|l|c|c|c|c|c|}
\hline Date Range & $\mathbf{n}$ & Breakpoint & Breakpoint (Pr>F) & Breakpoint (Pr $>$ F) & Regression (Pr $>$ F) \\
\hline $1841-1920$ & 225 & $1920+$ & 0.5212 & & 0.0211 \\
\hline $1920-1990$ & 886 & $1920+$ & & $<0.0001$ & \\
\hline
\end{tabular}

+Convergence was met for the piecewise regression models for these birth year subsets.

Pre-print version. Visit http://digitalcommons.wayne.edu/humbiol/ after publication to acquire the final version. 
Table 5. Examination of correlation among the residuals for the male dataset

\begin{tabular}{|l|c|c|c|c|}
\hline Covariance Parameters & Estimate & Standard Error & Z Value & $\operatorname{Pr} \mathbf{}$ \\
\hline AR(1) & -0.00449 & 0.03134 & -0.14 & 0.8861 \\
\hline Residuals) & 6.4105 & 0.2745 & 23.36 & $<0.0001$ \\
\hline Original Model* & $6.5149 *$ & & & \\
\hline
\end{tabular}

*The mean square error of the model obtained from the NLIN procedure

Pre-print version. Visit http://digitalcommons.wayne.edu/humbiol/ after publication to acquire the final version. 
Table 6. Examination of normality among the residuals for the male dataset

\begin{tabular}{|l|c|c|c|c|}
\hline Date Range & $\mathbf{n}$ & Breakpoint & & Shapiro-Wilk (Pr>F) \\
\hline $1841-1920$ & 225 & $1920^{\dagger}$ & 0.1890 & \\
\hline $1920-1990$ & 886 & $1920^{\dagger}$ & & 0.0145 \\
\hline
\end{tabular}

Pre-print version. Visit http://digitalcommons.wayne.edu/humbiol/ after publication to acquire the final version. 
Table 7. Piecewise regression fit results for the female dataset.

\begin{tabular}{|l|c|c|c|c|c|}
\hline Date Range & $\mathbf{n}$ & Breakpoint & Breakpoint (Pr>F) & Breakpoint (Pr>F) & Regression (Pr>F) \\
\hline $1846-1920$ & 214 & $1920^{\dagger}$ & 0.1683 & & \multirow{2}{*}{0.1021} \\
\hline $1920-1986$ & 458 & $1920^{\dagger}$ & & 0.0303 & \\
\hline
\end{tabular}

+Convergence was met for the piecewise regression models for these birth year subsets.

Pre-print version. Visit http://digitalcommons.wayne.edu/humbiol/ after publication to acquire the final version. 
Table 8. Examination of correlation among the residuals for the female dataset

\begin{tabular}{|l|c|c|c|c|}
\hline Covariance Parameters & Estimate & Standard Error & Z Value & $\operatorname{Pr} \mathbf{}$ \\
\hline AR(1) & -0.08337 & 0.04173 & -2.00 & 0.0458 \\
\hline Residuals) & 4.7642 & 0.2622 & 18.17 & $<0.0001$ \\
\hline Original Model* & 4.8013 & & & \\
\hline
\end{tabular}

*The mean square error of the model obtained from the NLIN procedure

Pre-print version. Visit http://digitalcommons.wayne.edu/humbiol/ after publication to acquire the final version. 
Table 9. Examination of normality among the residuals for the female dataset

\begin{tabular}{|l|c|c|c|c|}
\hline Date Range & $\mathbf{n}$ & Breakpoint & & Shapiro-Wilk (Pr>F) \\
\hline $1846-1920$ & 214 & $1920^{\dagger}$ & 0.2998 & \\
\hline $1920-1986$ & 458 & $1920 \dagger$ & & 0.1579 \\
\hline
\end{tabular}

Pre-print version. Visit http://digitalcommons.wayne.edu/humbiol/ after publication to acquire the final version. 
Figure 1. Linear regression and LOESS regression of vertical head diameter on year of birth for males

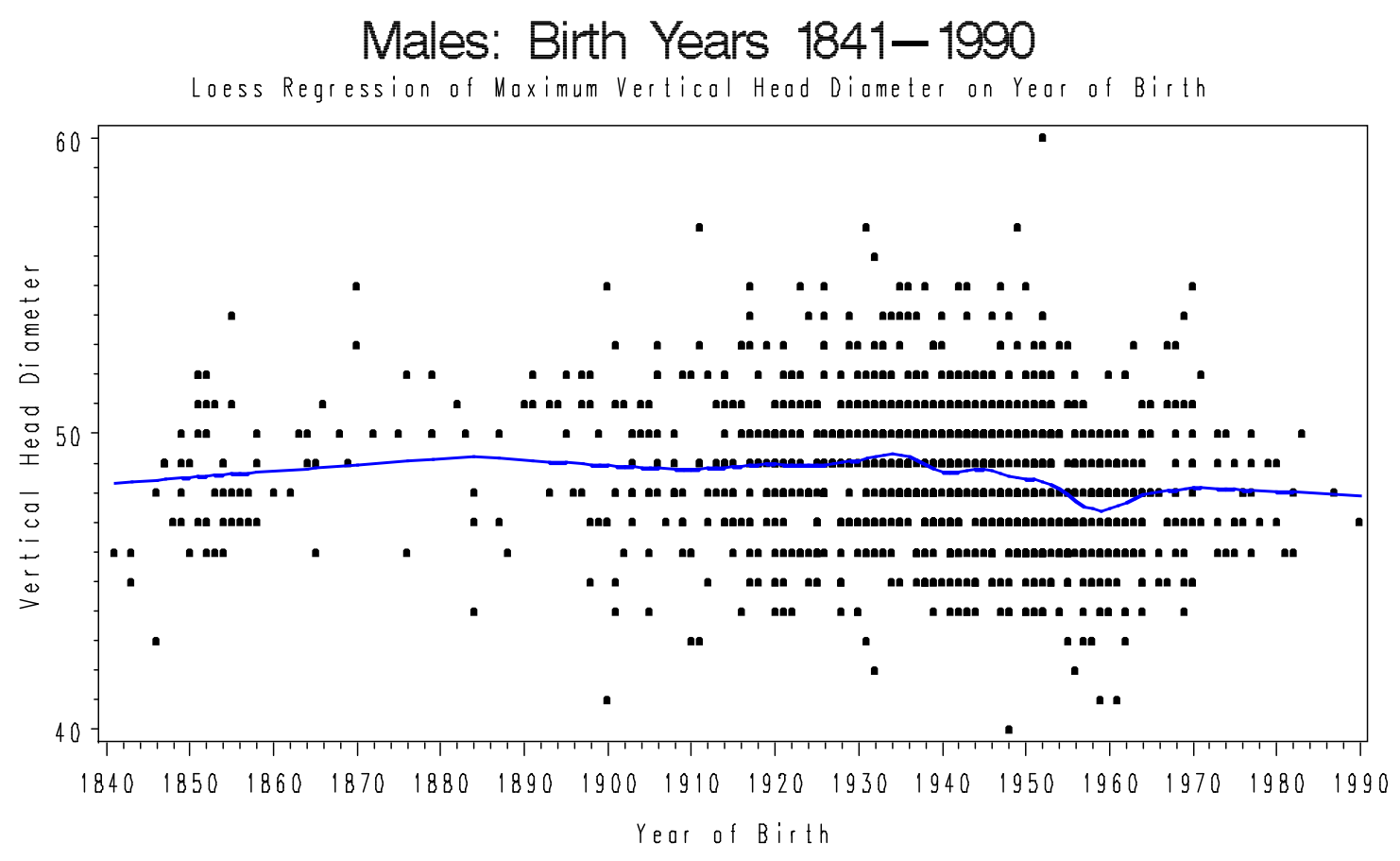

Pre-print version. Visit http://digitalcommons.wayne.edu/humbiol/ after publication to acquire the final version. 
Figure 2. Piecewise regression of vertical head diameter on year of birth for males.

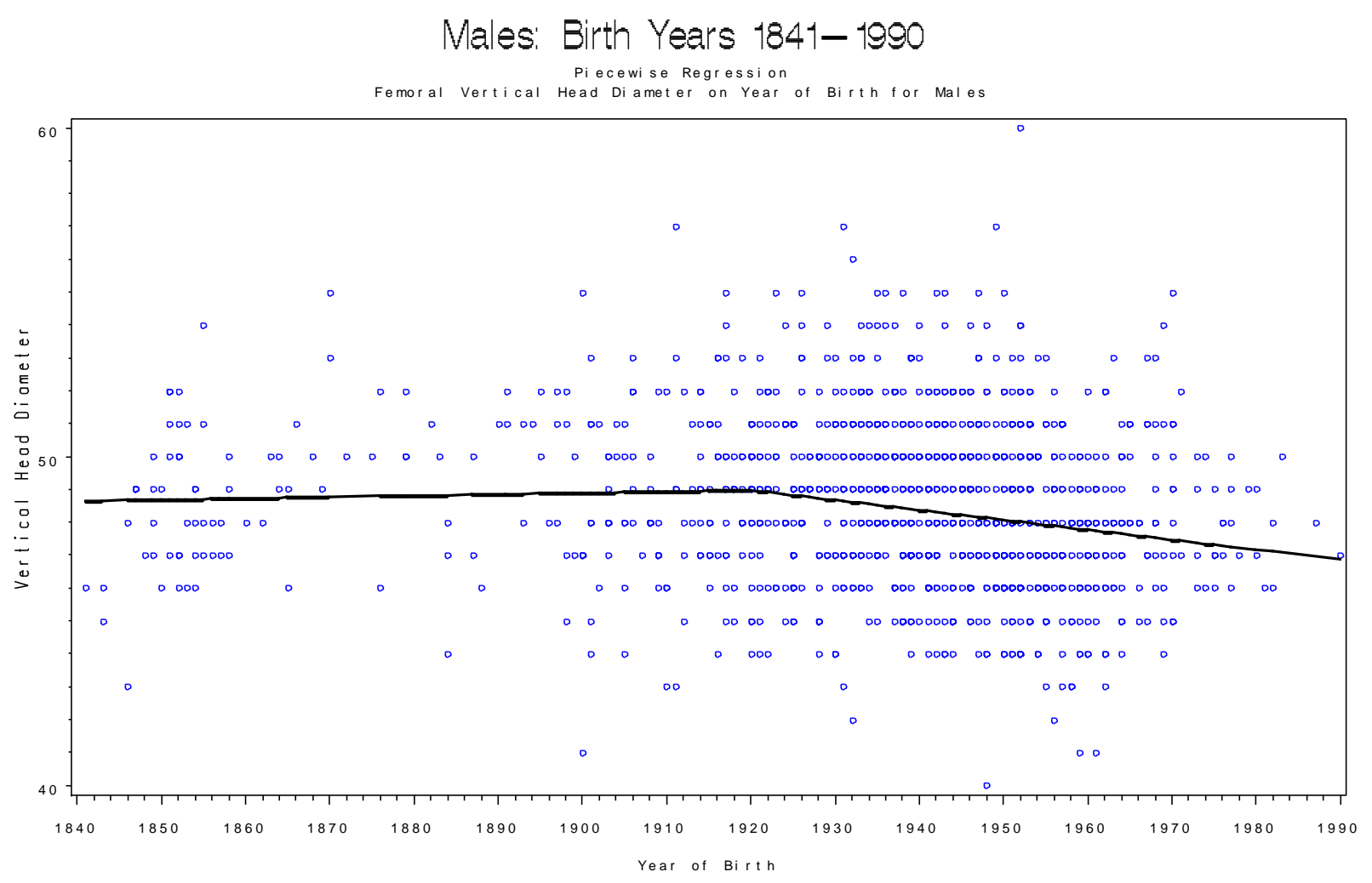

Pre-print version. Visit http://digitalcommons.wayne.edu/humbiol/ after publication to acquire the final version. 
Figure 3. Linear regression and LOESS regression of vertical head diameter on year of birth for females

\section{Females: Birth Years 1846-1986}

Loess Regression of Maximum Vertical Head Di ameter on Year of Birth

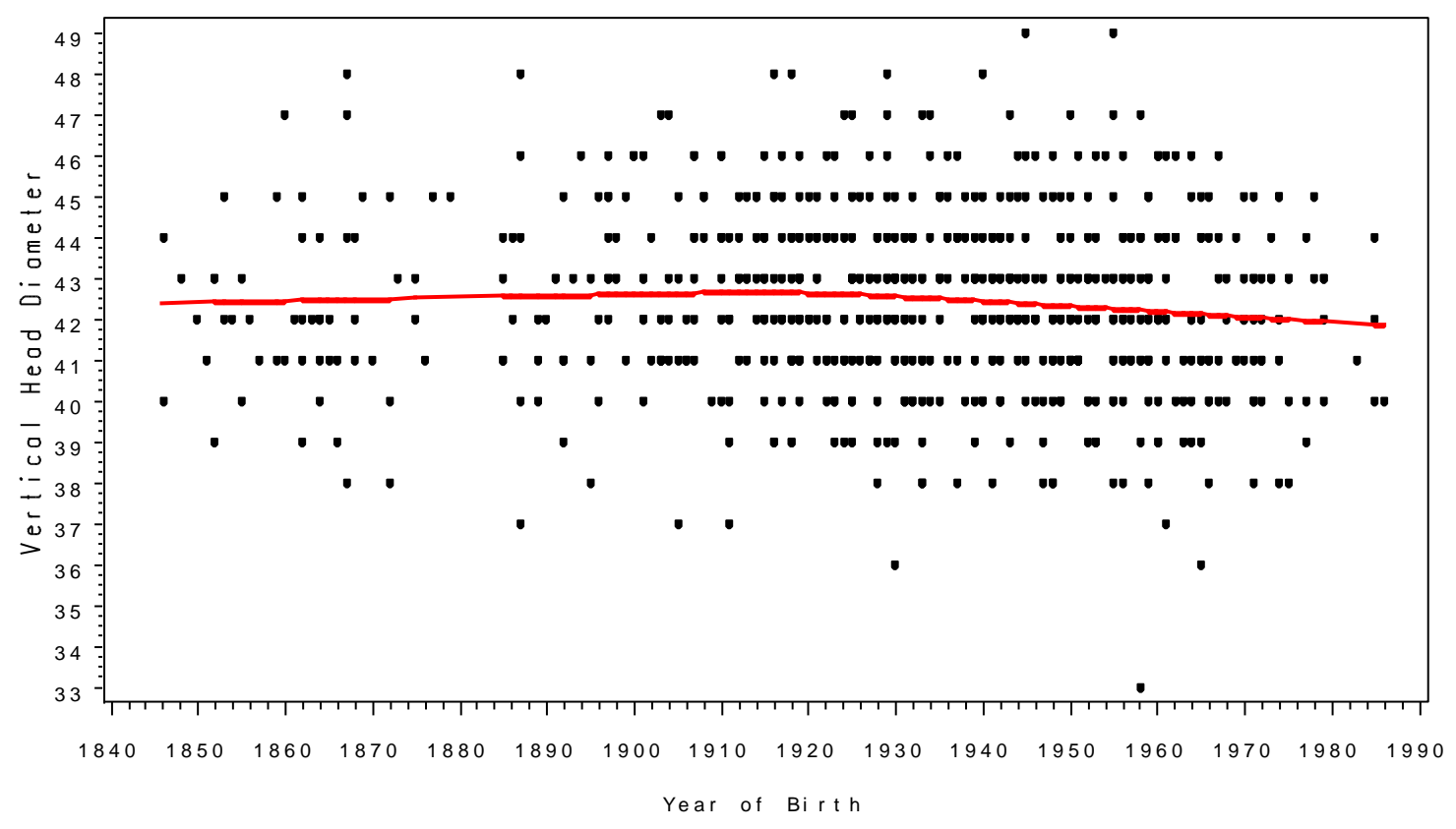

Pre-print version. Visit http://digitalcommons.wayne.edu/humbiol/ after publication to acquire the final version. 
Figure 4. Piecewise regression of vertical head diameter on year of birth for females.

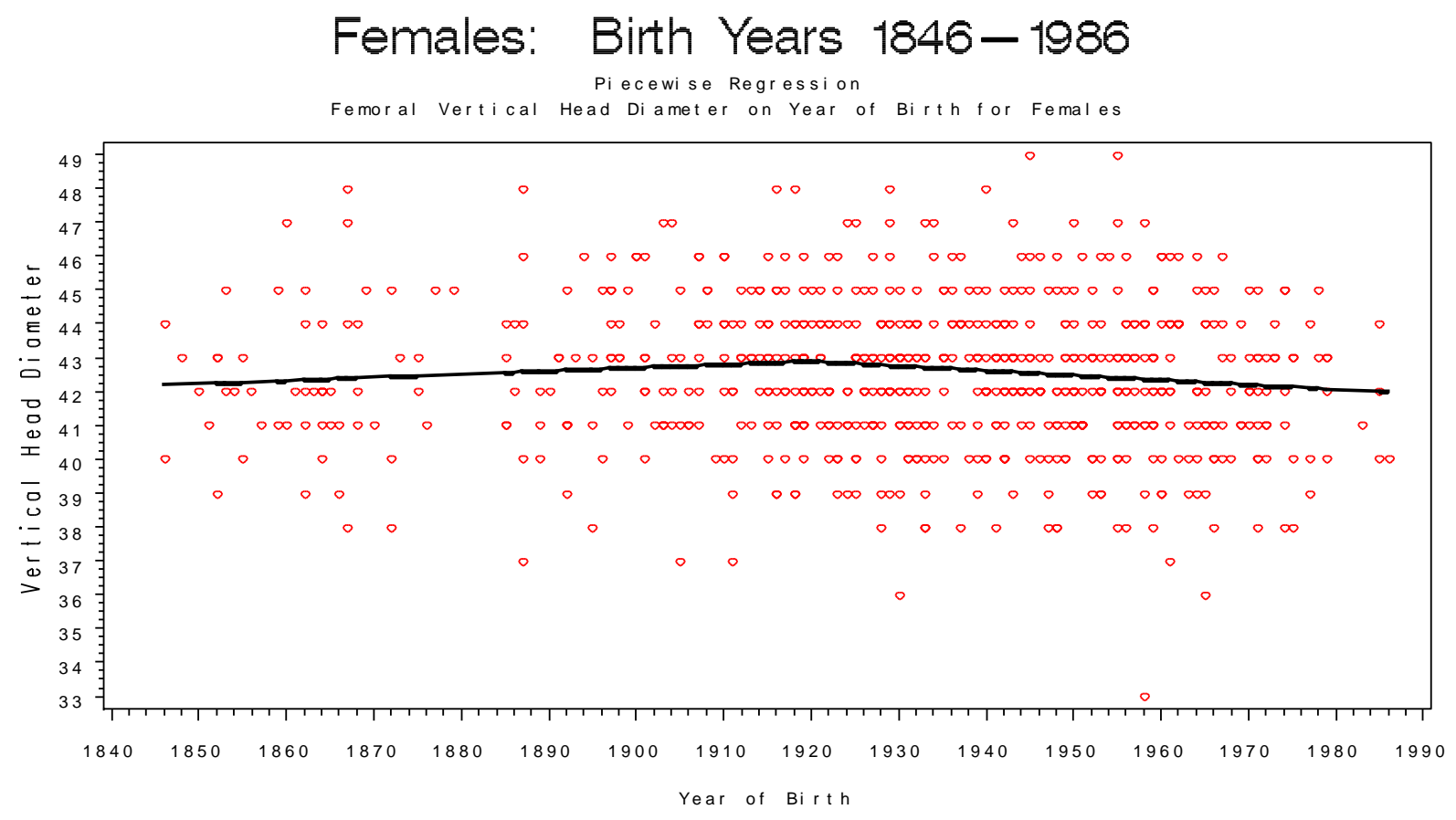

Pre-print version. Visit http://digitalcommons.wayne.edu/humbiol/ after publication to acquire the final version. 